\title{
Enhancing seedling production of black velvet tamarind (Dialium guineense Willd) 1
}

\author{
C. N. C. Nwaoguala and A. U. Osaigbovo* \\ Department of Crop Science, Faculty of Agriculture, University of Benin, Benin City, NIGERIA \\ *Corresponding author. E-mail: gbovosa@yahoo.com
}

\begin{abstract}
The present investigation was conducted to enhance seedling production of Black Velvet Tamarind (Dialium guineense). Three different types (sets) of experiments were designed. The results showed no sprouting of the stem cuttings in the first type of experiment ( stem cuttings treated with Naphthalene Acetic Acid (NAA) and coconut milk). The second type of experiment (seeds subjected to some pre-sowing treatments using NAA, coconut milk, manual scarification and seeds soaked in water for $24 \mathrm{hrs}$ ) showed highly significant treatment effects for seed treatments and days after planting, DAP $(p<0.001)$, while time or duration of treatment was not significant. There were highly significant interaction effects for Treatment duration $\times$ Seed treatments and Treatment duration $\times$ Days after planting (DAP). Mean percentage germination was best at 2000ppm NAA (43.85\%), but was not significantly different from $1000 \mathrm{ppm}$, (40.28\%), water soaked (40.28\%) and manual scarification (38.88\%). Lower germination rates were observed for $500 \mathrm{ppm}(34.72 \%)$, normal or untreated seeds $(30.75 \%)$, and coconut milk $(28.38 \%)$. There were highly significant treatment effects $(\mathrm{p}<0.001)$ between the control (normal seeds) with $11.2 \%$ mean germination, cold treatment (stratification), $21.1 \%$ and manual scarification $33.7 \%$. DAP was also highly significant with the highest mean germination of $34.1 \%$ at 56DAP. Treatments $x$ DAP was highly significant $(p<0.01)$ in the third experiment (stratification, a cold temperature pre-sowing treatment). Soaking seeds for $24 \mathrm{hrs}$ before planting was adjudged the best treatment for enhancing seedling production in Dialium guineense in this study. It was the easiest and cheapest of all other treatments considered.
\end{abstract}

Keywords: Seedling, Black velvet tamarind, Dialium guineense

\section{INTRODUCTION}

Black velvet tamarind (BVT) Dialium guineense is an important multipurpose agroforestry crop (Nwaoguala $e t$ $a l .$, 2007). The wood is of significant importance in furniture, tools handle, firewood and charcoal. Fruits have high nutritional values, sweet and reach in vitamin C, lysine and tryptophan and serve as food supplement for many Nigerians (Ogbe and Egharevba, 1992). Other uses and medicinal values of BVT were already highlighted in Nwaoguala et al. (2007).

Efforts have been made in recent times to explore the feasibility of the domestication of this germplasm, and it has been found to exhibit uneven and poor seed germination resulting to poor seedling production due to thick and gelatinous seed coat that restrict germination. Aghatise and Egharevba (1994) reported that manual scarification had the highest percentage germination and significantly better than warm water $\left(60^{\circ} \mathrm{C}\right)$, hot water and acid treatment. Nwaoguala et. al (2007) reported $37.7 \%$ germination using $98 \%$ sulphuric acid as seed treatment which was significantly much better than $49 \%$ sulphuric acid, temperature treatments of $40^{\circ} \mathrm{C}, 60^{\circ} \mathrm{C}$ and $80^{\circ} \mathrm{C}$ respectively, manual scarification and control. Pre-sowing heat treatment of seeds of Dialium guineense as way of improving seed germination and seedling production is out of the question based on the findings Aghatise and Egharevba (1994) and Nwaoguala et al. (2007). Manual scarification though enhances seed germination, has been observed to be tedious and do lead to some damage or injury to the embryo and/or cotyledons and was not as good as scarifying with $98 \%$ sulphuric acid (Nwaoguala et al., 2007). More reliable ways of enhancing seedling production of this crop need to be developed in order to promote its domestication, conservation and future exploitation of its considerable economic potentials in agroforestry.

The objectives of this study were to find out if Dialium guineense can easily be propagated through stem cuttings treated with dilute concentration of NAA and coconut milk. To see if soaking the seeds in water for $24 \mathrm{hrs}$ and subsequently treatment with exogenous growth factor NAA and coconut milk could enhance seed germination. Lastly, was to test the effect of cold treatment (stratification) on seed germination when the seeds are kept in a freezer at about $4^{\circ} \mathrm{C}$ for two months. 


\section{MATERIALS AND METHODS}

The planting materials namely, the stem cuttings and the seeds of Dialium guineense were obtained from a mature and fruit bearing tree behind the Teaching and Research Farm of the Faculty of Agriculture, within the Ugbowo Main Campus of University of Benin, Benin City.

In Experiment I, stem cuttings were $20 \mathrm{~cm}$ long and the leaves were removed. The cuttings were immersed in solutions of 2000ppm, 1000ppm, and 500ppm NAA and sterilized coconut milk solution for 20,40 and 60 minutes duration respectively. The cuttings immersed in water only were used as controls. They were planted in small poly bags filled with sterile river sand. The experiment was laid out as a $3 \times 5$ factorial in randomized complete block design (RCBD) replicated four times.

In the Experiment II, all seeds were soaked in distilled

Table 1 a . Mean germination rate at 20, 40, and 60 minutes treatment duration in experiment.

\begin{tabular}{cc}
\hline Duration (mins) & Germination Rate \% \\
\hline 20 & 36.74 \\
40 & 35.29 \\
60 & 38.10 \\
\hline
\end{tabular}

Table 1b. Mean germination percentage rate for seed treatments.

\begin{tabular}{cc}
\hline Seed Treatments & Germination Rate $\%$ \\
\hline Coconut milk & $28.38^{\mathrm{d}}$ \\
Normal & $30.75^{\mathrm{cd}}$ \\
500ppm NAA & $34.72^{\mathrm{bc}}$ \\
Manual Scarification & $38.88^{\mathrm{ab}}$ \\
Water Only & $40.08^{\mathrm{ab}}$ \\
1000ppm NAA & $40.28^{\mathrm{ab}}$ \\
2000ppm NAA & $43.85^{\mathrm{a}}$
\end{tabular}

water for $24 \mathrm{hrs}$ before other treatments were applied. Treatment durations of 20,40, and 60 minutes was applied as one factor, while 2000ppm, 1000ppm 500ppm NAA, coconut milk, seeds soaked in water only, manually scarified seeds and normal (untreated seeds) were the levels of the second factor. Manual scarified and normal seeds were the controls. All experimental units of six seeds were planted in poly bags filled with sterile river sand and the germination rates were scored on daily bases for eight weeks starting from the second week. The experiment was therefore, a $3 \times 7 \times 7$ factorial in RCBD with four replications. In the Experiment III, all seeds of Dialium guineense were placed in freezer at about $4^{\circ} \mathrm{C}$ for two months. Seeds were planted along with manually scarified seeds and normal seeds as controls in poly bags filled with sterile river sand. The germination rates were scored on daily bases for eight weeks starting from the second week. The experiment was a $3 \times 7$ factorial in a completely randomized design with seven replications.

Data collected as percentage germination were subjected to analysis of variance (ANOVA).

\section{RESULTS}

The stem cuttings planted in the first set of Experiment did not sprout, thus no data were collected. The analysis of variance (ANOVA) for the second set of Experiment did not show significant duration of treatment effect. There were significant treatment effects $(p<0.001)$ for seed treatments and days after planting (DAP). There were also highly significant interaction effects for Duration $x$ Seed treatments $(p<0.01)$ and Seed treatments $x$ DAP $(p<0.001)$. Duration $x$ DAP and Duration $x$ Seed treatments $x$ DAP were not significant. The mean percentage germination rates for Duration, Seed treatments and DAP are presented in Tables $1 \mathrm{a}, 1 \mathrm{~b}$, and $1 \mathrm{c}$ Table 1c. Mean germination percentage rate over DAP .

\begin{tabular}{cc}
\hline DAP (days) & Germination Rate \% \\
\hline 14 & $19.45^{\mathrm{d}}$ \\
21 & $25.79^{\mathrm{c}}$ \\
28 & $31.75^{\mathrm{b}}$ \\
35 & $37.50^{\mathrm{b}}$ \\
42 & $44.84^{\mathrm{a}}$ \\
49 & $47.22^{\mathrm{a}}$ \\
56 & $50.40^{\mathrm{a}}$ \\
\hline
\end{tabular}

Table 2a. Mean percentage germination for the Seed treatments in Experiment III.

\begin{tabular}{cc}
\hline Seed Treatment & Germination Rate \% \\
\hline Normal & $11.22^{\mathrm{c}}$ \\
Cold treatment (Stratification) & $21.09^{\mathrm{b}}$ \\
Manual scarification & $33.67^{\mathrm{a}}$ \\
\hline
\end{tabular}

respectively, while graphical presentation of significant interaction effects for Duration $x$ Seed treatments and Seed treatments x DAP are shown in Figs 1a and 1b respectively. The ANOVA of the third set of Experiment on seed stratification showed a highly significant $(\mathrm{p}<0.001)$ difference in mean percentage germination rates between cold treatment (stratification), manual scarification and normal seeds. Mean percentage germination rates over DAP was also highly significant $(\mathrm{p}<0.001)$ as well as those of Treatments x DAP interaction effects $(\mathrm{p}<0.01)$. The tables of means for the treatments in Experiment III are presented in Tables $2 \mathrm{a}$ and $2 \mathrm{~b}$. Graphical presentation of Treatments x DAP effects is shown in Fig. 2.

\section{DISCUSSION}

Enhancing seedling production in Dialium guineense in quantity and uniformity (quality) of germination has been the challenge of some previous and present studies 
(Aghatise and Egharevba 1994; Nwaoguala et al., 2007). The effort to propagate seedlings by cuttings treated with naphthalene acetic acid (NAA) an exogenous growth factor in this study proved abortive as none of the cuttings sprouted. This result however does not foreclose further investigations as soaking cuttings with resting buds in warm water, ethylene chlorohydrin, thiourea or rindite hastens termination of rest in 'Thompson seedless' (Weaver et al. 1961). Use of NAA may not have been very appropriate in this study as Weaver (1963) reported that Gibberellin delays termination of rest and that NAA causes some delay, while exogenous application of Indolebutric acid (IBA) at a concentration of 1000ppm hastens termination of rest. It may also be necessary in order to achieve the goal to determine the best time to

Table 2b. Mean germination percentage rate over DAP.

\begin{tabular}{cc}
\hline DAP (days) & Germination Rate \% \\
\hline 14 & $4.76^{\mathrm{d}}$ \\
21 & $11.11^{\mathrm{d}}$ \\
28 & $20.62^{\mathrm{c}}$ \\
35 & $23.81^{\mathrm{bc}}$ \\
42 & $27.78^{\mathrm{abc}}$ \\
49 & $31.75^{\mathrm{ab}}$ \\
56 & $34.13^{\mathrm{a}}$ \\
\hline
\end{tabular}

sprout stem cuttings as buds of woody plants such as grapes and other tree fruits undergo a period of dormancy each year, the length varying with species (Weaver et al. 1961). Discovering a vegetative propagation procedure for producing large numbers of seedlings of Dialium guineense would be very desirable in achieving the aim of this study.

Seed treatments have been found effective in this study and seem necessary in order to enhance seedling production. There was an advantage of treating seeds with water, manual scarification, and NAA over the control or untreated seeds, with 2000 ppm NAA having the highest germination percentage (43.85\%), though not significantly different from other treatments - 1000ppm, water only and manual scarification (Table 1b). This higher response to germination with NAA is indicative of positive response in similar reports of Burns and Coggins (1969) with seeds of Citrus sinensis using Gibberellins and Ashiru (1969) with seeds of Cola nitida using kinetin as well as thiourea and thiourea dioxide. More exogenous growth factors may need to be tested to see if germination rate could be raised further than hitherto.

Water as a seed treatment in this study proved to be relatively reliable procedure that could be easily adapted even by end users with little or no technical and economic

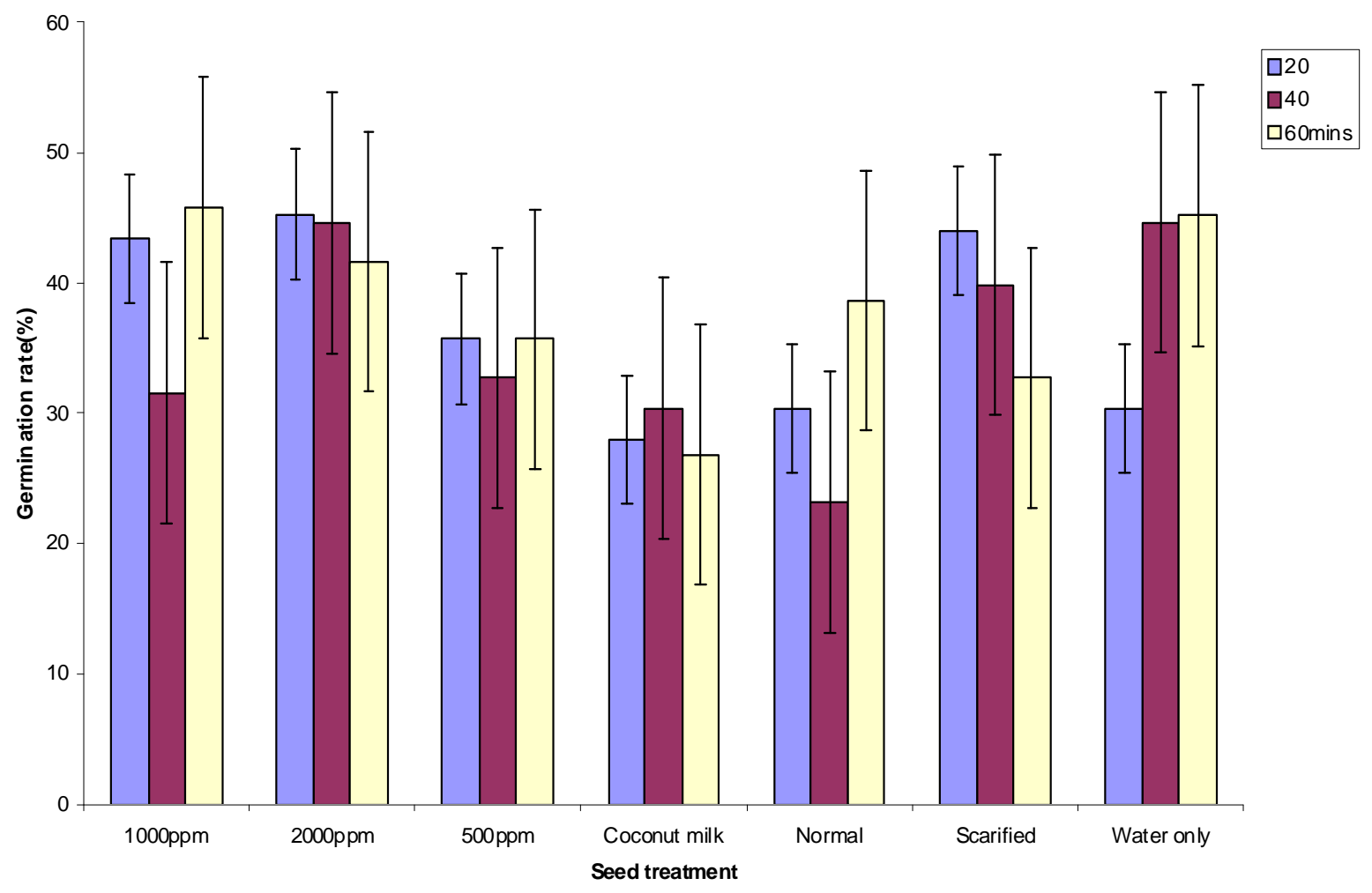

Fig. 1a: Percentage germination rates of seed treatments over duration. 
know how. Soaking seeds of Dialium guineense for twenty-four hours enhanced seed germination significantly from the control and not statically different from those treated with growth regulators. Using water as a seed treatment therefore would not only be easy, but also affordable. More investigation on the use of water may be promising to further enhance seed germination. The result on cold treatment as a way of enhancing seed germination and seedling production in Dialium guineense was comparatively low, although it was better than the normal (untreated seed), it was significantly lower than the standard (manual scarification of Aghatise and Egharevba, 1994). See Table 2a and Fig. 2.

The results in this study as shown in Figs $1 \mathrm{~b}$ and 2 indicate that for all seed treatments, there was increase in seed germination over time, up to 56 DAP or more. However, there was decrease in germination rate over DAP for manually scarified treatment (Fig 1b). The former is indicative that there may be some factors probably inhibitors responsible for the recalcitrant attribute of Dialium guineense seeds, the effect that wanes as from six weeks after planting (42DAP). It may be necessary to identify the inhibitor(s) involved as to know possible antidote to neutralize its effects as would give more uniform and rapid germination of seeds. While the decrease in germination rate for manually scarified treatment was due to seedlings mortality as a result of damage to embryo/cotyledon during scarification, another disadvantage of this method apart from it also being tedious.

Despite what has been reported so far, the challenge of developing a procedure to attain more than $70 \%$ uniform

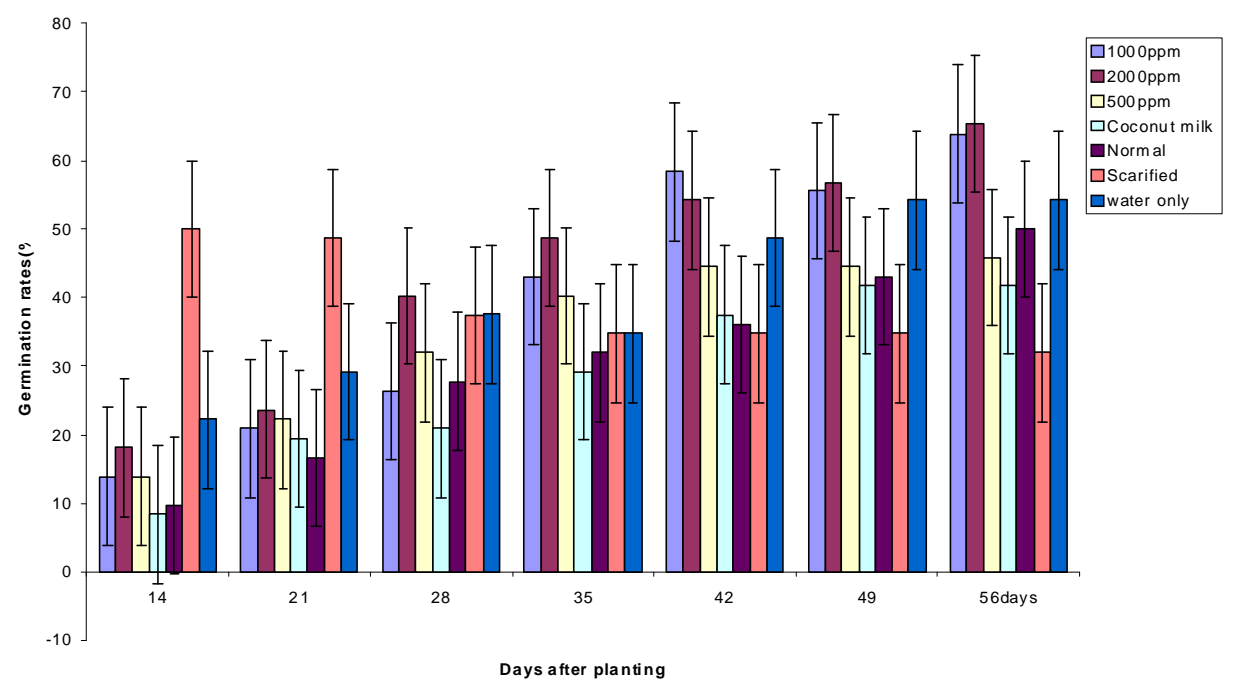

Fig. 1b. Percentage germination rates of seed treatments over days of planting (DAP).

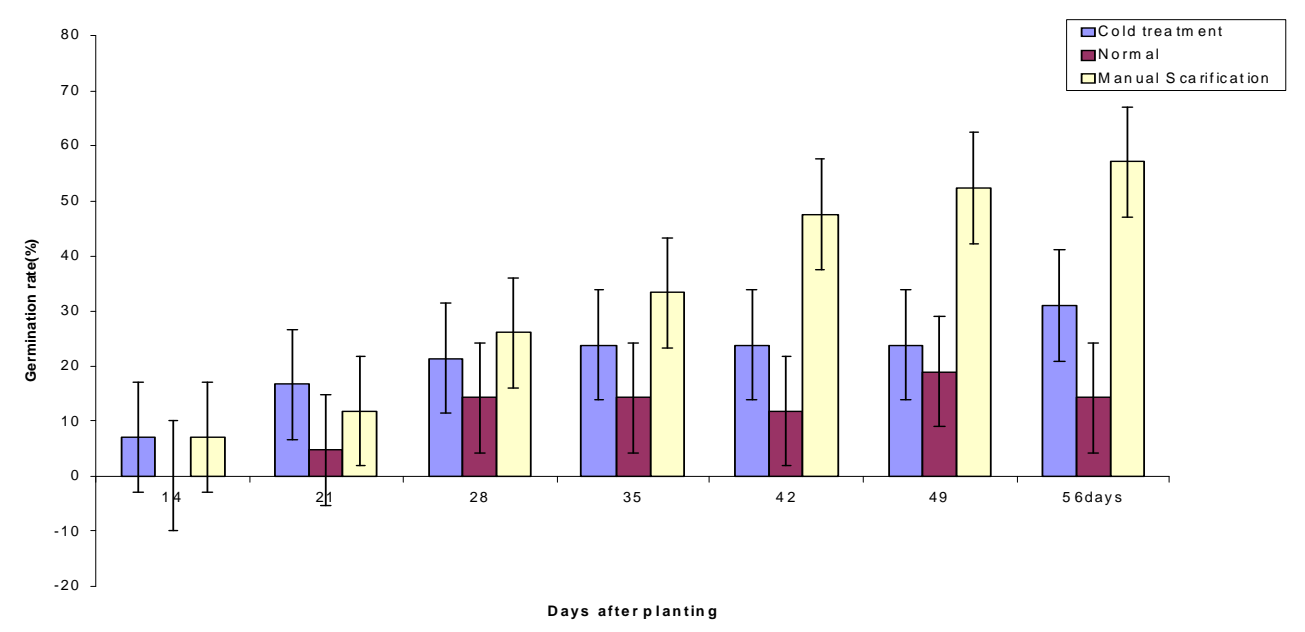

Fig. 2. Percentage germination rates of seed treatments over days after planting (DAP). 
seed germination still remains and would need to be overcome.

\section{ACKNOWLEDGEMENT}

The authors wish to acknowledge Miss Rhotos Ariole for her assistance with data collection.

\section{REFERENCES}

Aghatise, O. V. and Egharevba, R. K. (1994). Response of Dialium guineense to pregermination treatments. Nitrogen Fixing Tree Report 12: 54 - 55

Ashiru, G. A. (1969). Effect of kinetin, thiourea and thiourea dioxide, light and heat on seed germination and seedling growth of Kola (Cola Nitida Ventenant) (Schoft and Endlicher). JourAmer. Soc. Hort. Sci. 94:429-432.

Burns, R. M. and Coggins, C. W. Jr. (1969). Sweet orange germination and growth aided by water and gibberellins seed soak. Calif. Agr. 23:18-19.

Ogbe, D. F. and Egharevba, R. K. (1992). Indigenous food plants. Field survey of indigenoius and useful plants, their preparation for food and home garden Edo/Delta States of Nigeria. Univ. Prog. on Natural Resources in Africa 1: 132 - 134

Nwaoguala, C.N.C, Osaigbovo, A.U. and Orhue, E.R. (2007). Seed treatment for development of seedlings of Black Velvet Tamarind (Dialium guineense). African Journal of General Agriculture 3:49 - 51.

Weaver, R. J. (1963). Experiments on thinning Grapes with Alpha-Naphthalene Acetic Acid and Dinitro-Secbutylphenol. Vitis 4:1-10

Weaver, R. J., McCune, S. B. and Coombe, B. G. (1961). Effect of Various Chemical and Treatments on Rest Periods of Grape Buds. Amer. Jour. Enol. Vitic. 12:131-142. 